ÉGYPTE monde arabe

\section{Égypte/Monde arabe}

33 | 1998

Travailleurs et industrie à l'heure des réformes

économiques

\title{
La montée du chômage en Égypte (1960-1995)
}

\section{Philippe Fargues}

\section{(2) OpenEdition}

Journals

Édition électronique

URL : https://journals.openedition.org/ema/1585

DOI : 10.4000/ema.1585

ISSN : 2090-7273

Éditeur

CEDEJ - Centre d'études et de documentation économiques juridiques et sociales

Édition imprimée

Date de publication : 30 juin 1998

Pagination : 147-180

ISSN : 1110-5097

\section{Référence électronique}

Philippe Fargues, «La montée du chômage en Égypte (1960-1995) », Égypte/Monde arabe [En ligne], 33 | 1998, mis en ligne le 08 juillet 2008, consulté le 07 juillet 2022. URL : http:// journals.openedition.org/ema/1585; DOI : https://doi.org/10.4000/ema.1585

Ce document a été généré automatiquement le 7 juillet 2022

Tous droits réservés 


\title{
La montée du chômage en Égypte (1960-1995)
}

\author{
Philippe Fargues
}

Parmi les arguments qui remettent en question le classement usuel des États entre pays industriels et pays en développement, la montée du chômage au cours des deux dernières décennies devrait venir en bonne place tant elle semble transcender cet ordre binaire du monde. Avec un étonnant synchronisme, on l'enregistre dans les contextes nationaux les plus divers, comme si le chômage relevait au contraire d'un ordre global, faisait partie des évolutions partagées et manifestait lui aussi cette interdépendance planétaire aujourd'hui redécouverte. Le chômage n'oppose pas tant des pays entre eux, comme le veut une opinion tenace selon laquelle il est le tribut payé par certains aux nouvelles formes de la concurrence internationale ${ }^{1}$, qu'il ne sanctionne au sein de chaque pays des parcours individuels particuliers (Rosanvallon, 1995), des combinaisons défavorables de l'inégalité des chances et des environnements économiques. La compréhension du phénomène, aussi global soit-il, passe par celle des conditions individuelles et locales y conduisant et de l'évolution de ces conditions. Partout, et les points communs s'arrêtent peut-être là, sont considérées comme chômeurs les personnes qui ne trouvent pas à s'employer bien qu'elles le cherchent, ce qu'elles font généralement dans le lieu où elles vivent. Quelles sont les caractéristiques distinctives de ces personnes et quelles sont celles des lieux où elles se trouvent? Telles sont les deux questions qui seront examinées successivement, après un bref rappel des éléments d'une discussion de la notion de chômage. Une analyse plus complète des déterminants du chômage devrait également prendre en compte le contexte international avec lequel l'Égypte interagit: au niveau régional, elle s'intéresserait à l'évolution des marchés du travail immigré dans le golfe Arabo-Persique ou en Libye et, au niveau international, à la compétitivité de l'économie égyptienne, au rôle des institutions financières internationales dans l'inspiration des politiques nationales susceptibles d'affecter l'emploi, etc. ${ }^{2}$ 


\section{Les ambiguïtés de la mesure du chômage}

2 En Égypte, le chômage est une catégorie administrative au moins aussi ancienne que la statistique. Dès 1848 , le premier recensement de la population identifie des chômeurs (battâl, mot toujours en usage), comme des personnes possédant en général une profession mais présentement sans emploi : 706 chômeurs sont ainsi répertoriés au Caire, soit près de $1 \%$ de la population active, dont les chômeurs sont considérés comme l'une des composantes ${ }^{3}$. Leur proportion ne changera pas beaucoup durant plus d'un siècle. Dans les années soixante et la première moitié des années soixante-dix, elle tourne encore autour de $2 \%$ chez les hommes. Vers 1975, commence une ascension qui sera presque continue jusqu'en 1995, date des dernières données disponibles ${ }^{4}$. Le taux de chômage atteint alors 11,3 \% pour l'ensemble des actifs : 7,5 \% chez les hommes et trois fois plus chez les femmes (24,1\%). Le pays compte alors 1,9 million de chômeurs, répartis à égalité entre hommes et femmes. Ces chiffres, fournis par l'enquête sur l'emploi, sont contestés par plusieurs analystes auxquels nous renvoyons le lecteur et dont nous reprenons la conclusion : faute d'autres données, ce sont ceux-là que nous utiliserons. Ils sous-estiment vraisemblablement le nombre des chômeurs, qui dépasserait nettement 2 millions (12 à $15 \%$ des actifs), pour la raison suivante : être enregistré comme chômeur par une enquête suppose que l'on déclare chercher du travail, démarche dont plus d'un serait dissuadé par une certitude d'échec (Fergany, 1997). Qu'elle reflète fidèlement ou non le phénomène, la montée de l'indicateur de chômage au cours des vingt années passées est cependant un fait (graphique 1 et tableau 1$)^{5}$. Comment l'interpréter?.

3 Trois phénomènes sont susceptibles d'y concourir.

1. L'importance croissante d'une exclusion effective du travail serait une première cause de l'élévation des indicateurs de chômage. Elle confond elle-même une diversité d'évolutions. Il peut se faire que des individus présentant des caractéristiques semblables à ceux qui hier trouvaient un emploi n'en trouvent plus aujourd'hui : c'est alors l'offre d'emploi qui est en cause. Le déséquilibre peut également provenir d'une demande plus abondante, si des personnes qui n'auraient point cherché d'emploi hier en cherchent un aujourd'hui, sans succès. Il peut enfin résulter d'une modification qualitative de la demande, si les individus qui arrivent désormais sur le marché du travail présentent des caractéristiques différentes de ceux qui les avaient précédés. Ce premier ensemble de raisons a fait l'objet des travaux les plus nombreux, notamment de la part des économistes ${ }^{6}$.

2. L'amélioration continue de la mesure statistique de l'exclusion du travail serait une deuxième raison. L'irruption du chômage dans le débat public et la diffusion d'outils constamment affinés par le Bureau international du travail et d'autres organisations internationales auraient alerté les gouvernements sur l'importance d'une question sociale et politique $^{7}$ et sur la nécessité de mieux la connaître afin de mieux la traiter. Quel que soit l'affinage de la mesure, le résultat dépend par ailleurs de l'adéquation des outils à rendre compte des situations réelles. On a ainsi abondamment critiqué l'assimilation du chômage à l'inoccupation totale au cours d'une période de temps: une personne peut se trouver en situation d'emploi, voire de suremploi selon le critère du temps passé sur un lieu de travail (pluriactivité incluse) tout en étant sous-employée (voire inemployée) selon un critère de productivité du travail ${ }^{8}$. Les statisticiens ont contribué à affiner la mesure du chômage, à adapter un instrument statistique importé à la situation spécifique du travail en Égypte, mais sans s'interroger cependant sur la catégorie elle-même : pour eux, la barrière entre chômeurs et occupés se situe dans une gradation différente de celle des pays où les définitions ont été forgées, mais elle existe bel et bien. 
3. La popularisation de la catégorie de chômeur, c'est-à-dire la diffusion de l'idée que l'exclusion du travail crée un groupe distinct dans la société, est enfin une troisième cause possible. Le chômage est estimé sur la base de résultats d'enquêtes dans la population, c'està-dire en dernier ressort du jugement que les individus formulent sur leur propre situation. Les représentations du phénomène influencent dès lors sa mesure. Afin de contourner l'écueil de la subjectivité du répondant, des règles ont été fixées pour limiter sa marge d'initiative dans l'appréciation de son état. L'état de chômeur est déterminé a posterioripar le statisticien en deçà d'un seuil minimum de durée de travail au cours d'une période de référence fixée par lui, la semaine ou le mois précédant le recensement ou l'enquête selon les opérations. Il revient simplement à l'enquêté de conformer sa déclaration à cette définition. Croyant éliminer la subjectivité, on ne fait que déplacer l'objet sur lequel elle porte : il n'est pas demandé à l'enquêté s'il est chômeur, mais s'il a travaillé. Ce faisant, on postule que le travail, comme catégorie dichotomique, est un état bien reconnu quelle que soit la situation dans laquelle il s'exerce, qu'il n'est susceptible d'aucune ambiguïté d'interprétation'. La marge laissée à l'appréciation individuelle est amplifiée en Égypte par le fait que l'état de chômeur est une catégorie simplement statistique, mais non juridique. Il n'existe en effet pas de système de protection ou de prise en charge du chômeur, par lequel il serait reconnu et se reconnaîtrait comme tel. Il n'existe donc pas de contrôle de conformité d'une situation individuelle à une définition administrative.

\section{Le profil du chômeur}

4 Le chômage est-il un accident de parcours auquel un grand nombre de personnes seraient exposées, avec un risque variable selon les situations mais pour des raisons d'ordre d'abord macro-économique, ou caractérise-t-il plutôt certaines situations et parcours bien particuliers en épargnant relativement les autres? Est-il un risque suffisamment partagé pour être considéré comme aléatoire, ou plutôt une étape hautement probable pour une partie seulement de la population, attachée à des configurations individuelles non généralisables?

\section{Jeunesse}

5 Le chômage est d'abord un mode d'entrée dans la vie active. Les personnes n'ayant jamais travaillé forment la grande majorité des chômeurs égyptiens : 89 \% d'après le recensement de 1996,96\% d'après l'enquête sur l'emploi de $1995^{10}$. Ce sont donc des jeunes: $94 \%$ des chômeurs ont moins de 30 ans (1995). Combien de jeunes commencent-ils leur vie active par une période de chômage ? C'est une autre question, que les données existantes éclairent mal ${ }^{11}$. Pour 1995, on peut avancer une proportion variant entre le tiers et la moitié : à 20-24 ans, âge auquel la moitié environ des Égyptiens se considèrent comme faisant partie de la population active (56\% des hommes, $35 \%$ des femmes), les chômeurs représentent $42 \%$ des actifs ( $31 \%$ chez les hommes, 59 \% chez les femmes) (tableau 2).

6 La faiblesse du chômage parmi les personnes ayant déjà exercé un emploi est une autre de ses caractéristiques, qui distingue radicalement la situation égyptienne de celle de pays plus industrialisés, en Europe par exemple où une montée du chômage secondaire (après un emploi) a accompagné les restructurations économiques récentes. Mieux, la part du chômage secondaire en Égypte, très faible déjà dans les années soixante-dix, a encore diminué depuis, comme si la montée du chômage s'était concentrée sur la 
recherche du premier emploi. L'abandon progressif de la politique de plein emploi instaurée par le régime socialiste au début des années soixante a sans doute retardé l'occupation d'un premier emploi et rendu sa recherche plus longue et plus difficile. D'après les enquêtes sur la main-d'œuvre, la nouvelle politique ne semble cependant pas avoir mis au chômage des personnes précédemment employées. Cela ne veut pas dire que la politique de réforme économique, consacrée par les accords de stabilisation économique et d'ajustement structurel passés avec le Fonds monétaire international et la Banque mondiale en novembre 1991, ne produira aucun autre effet pervers dans le domaine de l'emploi, mais que ses résultats tangibles se limitent jusqu'à présent à ralentir la création d'emploi dans le secteur public, voire à la bloquer dans certains domaines de l'économie privée où le choix des investisseurs se porte sur des activités à forte intensité de capital, plutôt qu'à dessaisir de leur emploi ceux qui en possèdent $u^{12}$. Que le chômage soit presque exclusivement une étape initiale de la vie active ne signifie pas que celle-ci soit courte. La recherche d'un emploi semble en effet durer plusieurs années: en 1988, seule date pour laquelle l'information est disponible, les chômeurs de 20-24 ans avaient derrière eux une période continue de non-emploi absolu de 125 semaines en moyenne: plus de deux années de recherche infructueuse d'un emploi (Fergany, 1990). Un cinquième d'entre eux sortait d'ailleurs d'une définition stricte du chômage, pour la raison que leur recherche était demeurée passive, limitée à l'attente d'une lettre d'embauche dans l'administration publique (Fergany, 1990). Étape initiale longue, le chômage est en outre une étape finale pour de nombreuses femmes, qui sortent de la population active sans avoir jamais trouvé d'emploi et avec le chômage pour unique expérience de l'activité. ${ }^{13}$

\section{Parité des sexes, mais non égalité}

7 La naissance du chômage féminin est l'un des changements les plus marquants des trois dernières décennies. On ne comptait que 6 \% de femmes parmi les chômeurs de 1962 (8 400 femmes pour 134100 hommes); elles en forment désormais 48\% (919 300 femmes pour 991100 hommes en 1995). Le nombre de femmes au chômage a été multiplié par plus de 100 dans le temps où celui des hommes était multiplié par 7 (graphique 2).

8 La parité numérique entre hommes et femmes dans la population des chômeurs cache cependant deux différences fondamentales entre les sexes. La première est la probabilité d'être au chômage, trois fois plus élevée chez les femmes que chez les hommes (deux fois plus, chez les moins de 30 ans). L'explication réside dans le fait qu'une minorité seulement des femmes entrent dans la définition de la population active, alors que la quasi-totalité des hommes en font partie. L'interprétation du faible niveau de la participation des femmes aux activités économiques en Égypte sort toutefois du champ de cet article ${ }^{14}$. La seconde différence entre les sexes réside dans l'avenir des chômeurs. À l'égalité devant le chômage comme étape initiale de la vie active, succède en effet l'inégalité devant la sortie du chômage, c'est-à-dire devant l'emploi ultérieur. Que deviennent, quelques années plus tard, les jeunes chômeurs? Faute d'enquête appropriée, nous essaierons d'apporter des éléments de réponse en rapprochant deux enquêtes successives.

9 La mise en série des enquêtes sur l'emploi de 1990 et 1995 permet d'observer deux groupes de générations, celles qui sont nées en 1971 -1975 et en 1966-1970, à chacune 
de ces deux dates ${ }^{15}$. Le suivi des générations 1971 -1975 nous informe sur ce qui survient autour du vingtième anniversaire (entre 15-19 et 20-24 ans : première phase); celui des générations 1966-1970 sur ce qui survient autour du vingt-cinquième anniversaire (entre 20-24 et 25-29 ans : deuxième phase) ${ }^{16}$. On ne peut cependant pas mettre bout à bout ces bribes d'histoire de vie pour reconstituer toute la tranche d'âge qui va de 15 à 30 ans, car ces deux groupes de générations n'ont pas connu exactement les mêmes circonstances en matière d'emploi. La distinction de ces deux phases suffit à révéler une divergence profonde dans l'expérience des deux sexes.

Durant la première phase (graphique $3 \mathrm{~A}$ ), les expériences sont simplement parallèles. Ces cinq années d'âge, le début de la vie active pour beaucoup, sont celles où montent à la fois l'emploi et le chômage, pour les hommes comme pour les femmes, dans les villes comme dans les campagnes. Une première différence tient à la masse des actifs, chômeurs et occupés confondus, qui représentent à l'issue de ces cinq années une proportion plus élevée chez les hommes que chez les femmes et dans les campagnes que dans les villes : écart d'intensité entre les sexes - moins de femmes que d'hommes entreront finalement dans la vie active -mais de calendrier entre les secteurs de résidence - l'entrée dans la vie active est plus précoce dans les campagnes que dans les villes. Une seconde différence tient au poids relatif du chômage : chez les hommes, il est dès le départ (15-19 ans) moins important que l'emploi et il le reste, tandis que chez les femmes, il touche la majorité des actives (sauf à 15-19 ans, dans les seules campagnes). Plus de la moitié des femmes abordant la vie active le font ainsi en situation de chômage. En considérant les effectifs absolus, le chômage des jeunes apparaît d'ailleurs comme majoritairement féminin à 15-19 ans : 136300 femmes pour 107900 hommes. À 20-24 ans, l'écart a changé de sens, avec des effectifs au chômage de 430900 et 476200 respectivement.

11 C'est au cours de la deuxième phase (graphique 3B, graphique 4) que les évolutions divergent radicalement pour les sexes, de manière à peu près semblable dans les secteurs urbain et rural. Les hommes encore inactifs au début de l'intervalle entreront presque tous en activité, pour une part avec un emploi et pour une autre à la recherche d'un emploi. Le chômage masculin conserve à peu près son niveau initial en valeur absolue (diminution de 20700 en ville et de 14500 à la campagne), mais il se résorbe en valeur relative : la création d'emploi est ainsi la dynamique principale (+ 306100 en ville, +199800 à la campagne). C'est le contraire chez les femmes, pour qui la sortie d'activité est la dynamique principale. En ville, une faible création d'emploi (+ 12 800) n'explique qu'un dixième de la réduction du chômage féminin (- 103 400); à la campagne, on observe une réduction à la fois de l'emploi (- 61400) et du chômage des femmes (- 12 900), au profit de l'inactivité. Tandis que les hommes sortent du chômage en trouvant un emploi, quitte à réviser à la baisse leurs ambitions initiales, c'est en renonçant à exercer une activité économique que les femmes en sortent.

Cette dynamique de la résorption du chômage par l'emploi (hommes) ou par l'exclusion (femmes) détermine au-delà de 25 ans une polarité de la population que rien ne dessinait avant cet âge : les hommes sont employés et les femmes inactives. Doit-on l'attribuer à la seule exiguïté du marché du travail, ou également à des comportements familiaux qui limitent l'accès des femmes à ce marché, une fois leur mariage conclu ? À tout âge, le taux d'activité féminine est en effet trois fois plus élevé parmi les célibataires que parmi les non-célibataires ${ }^{17}$. Il existe bien des emplois féminins, mais la famille préfère les réserver aux femmes non mariées. 


\section{Handicap du diplôme} analphabètes et les personnes ayant une éducation primaire incomplète formaient la grande masse des chômeurs ( $87 \%$ ), comme d'ailleurs des personnes ayant un emploi. Les diplômés du secondaire ou du supérieur n'étaient qu'une petite minorité parmi les chômeurs $(1,6 \%)$ : l'État égyptien garantissait alors à tout diplômé un emploi dans la fonction publique. Une génération plus tard, en 1995, les rapports sont entièrement inversés: on ne compte plus parmi les chômeurs que 2,3\% d'analphabètes et de personnes sachant seulement lire et écrire, mais $96,3 \%$ de diplômés du secondaire ou du supérieur ${ }^{18}$. Le taux de chômage lui-même aurait plutôt diminué dans la population sans instruction scolaire $(0,4 \%)$ mais atteindrait $33,3 \%$ parmi les diplômés du secondaire, $19,4 \%$ avec une formation universitaire incomplète et $11,8 \%$ avec une formation universitaire complète. La montée du chômage s'est ainsi entièrement fixée sur les diplômés qui ont graduellement perdu la protection de l'État au fur et à mesure que leur masse s'amplifiait. S'agit-il pour tous d'un chômage stricto sensu, c'est-à-dire d'une non-participation absolue à toute activité économique? Certains ne se considèrent-ils pas comme chômeurs alors qu'ils exercent une activité occasionnelle, sous-qualifiée ou sous-rémunérée, pour la raison que celle-ci se situe bien en deçà de leurs attentes de diplômés ? ${ }^{19}$ Dans un cas comme dans l'autre, leur expérience consacre la fin d'une utopie portée par beaucoup de régimes socialistes dans les années de la construction du tiers-monde, celle de la libération des individus et du progrès social par l'instruction scolaire (tableaux 3 et 4, graphique 5).

Même s'il n'est devenu massif que récemment, le chômage des diplômés n'est pas nouveau. Il accompagne la fondation de l'université moderne et devient une question sociale dès les années trente (Farag, 1998). Il prend à ce moment le profil qu'il conserve aujourd'hui : ce ne sont pas les universitaires qu'il atteint le plus, mais les diplômés du secondaire (Farag, 1998). En 1937, un article passant en revue les «plaies économiques" de l'Égypte consacre une place importante au "chômage des intellectuels». "Les universités et les écoles en Égypte et à l'étranger délivrent annuellement des milliers de diplômes et de certificats aux jeunes Égyptiens dont la majorité a pour seul but l'emploi à des postes dans les administrations du gouvernement. Mais comme le nombre de ces postes est limité, l'État se trouve obligé de fermer ses portes à un grand nombre de ces intellectuels. [...] Manquant d'esprit de risque et d'initiative, handicapés par leur milieu, abandonnés par le législateur, ces intellectuels constituent une génération de transition, sacrifiée comme toutes les générations des périodes d'évolution.» (El Emary, 1937) L'actualité de ces propos n'échappera pas, en particulier le rôle accordé à l'initiative personnelle, privée, dans la sortie du chômage.

\section{Et le milieu social ?}

El Emery soulignait en 1937 un handicap du «milieu ». Il désignait par là l'origine sociale modeste, souvent rurale, de beaucoup de ceux qui ne parvenaient pas à réaliser dans la vie professionnelle les bénéfices de leur diplôme. Soixante ans plus tard, on trouve un même handicap attaché à la résidence rurale : la probabilité de s'y trouver au chômage, à diplôme égal, y est beaucoup plus forte qu'en ville, en particulier pour ceux

Égypte/Monde arabe, 33 | 1998 
qui ont arrêté leur scolarité après le certificat de fin d'études secondaires et pour les femmes (tableau 3). L'importance du chômage rural en valeur absolue a même de quoi surprendre, car on croirait les campagnes vouées plutôt au sous-emploi (plus de 901000 chômeurs ruraux pour un million d'urbains). Sans doute faut-il y voir en partie un effet des classifications administratives : sont considérées comme rurales toutes les communes périphériques des villes, de fait intégrées dans l'agglomération et dont on sait par ailleurs qu'elles regroupent des populations aux conditions de vie plus précaires. Mais il y a probablement là aussi l'expression d'une réelle convergence des milieux : les populations non agricoles occupent une place rapidement croissante dans les campagnes, où elles demeurent cependant plus éloignées des opportunités d'emploi. On ne sait rien des origines sociales des chômeurs: les enquêtes sur l'emploi ne comportent aucune des informations qui permettraient de les apprécier. On ignore de même leurs conditions de vie, car les enquêtes sur les dépenses et la consommation des ménages (le niveau de vie) distinguent le statut d'activité du chef de ménage, mais non celui des autres membres. La dernière en date (1995-1996) nous apprend ainsi que les membres d'un ménage dont le chef est chômeur effectuent des dépenses sensiblement inférieures aux autres ménages, dans tous les domaines de la consommation ${ }^{20}$. Les chefs de ménage ne représentent cependant qu'une toute petite minorité $(0,5 \%)$ parmi les chômeurs, dont la très grande majorité continue d'appartenir à leur ménage de naissance. On ne peut donc pas tenir cette infériorité du niveau de vie pour une caractéristique commune à tous les chômeurs. À défaut de données individuelles, la relation entre chômage et pauvreté ne peut être abordée que par des caractéristiques collectives, celles des milieux de résidence.

\section{Le contexte du chômage}

16 Le chômage varie fortement selon les lieux, aussi bien par le niveau que par révolution. À profil et parcours semblables, les individus ne rencontrent en effet pas partout la même situation. Bien que l'on n'ait en Égypte aucune enquête sur la démarche du chercheur d'emploi, on peut penser qu'elle se déroule dans un rayon étroit autour du domicile, tout au moins dans un premier temps. La faiblesse, voire l'inexistence d'un marché national de l'emploi occasionne vraisemblablement une mobilité spatiale très limitée du travail. Une analyse fine du contexte du chômage devrait donc serrer au plus près les personnes, dans des unités géographiques suffisamment petites pour correspondre à celles à l'intérieur desquelles l'information circule effectivement: les shiyâkha (quartiers de ville) et qurâ (villages et leur terroir) seraient par exemple une bonne échelle. La source privilégiée ici, l'enquête annuelle sur l'emploi, ne donne qu'une ventilation beaucoup plus large, celle des muhâfadhât (provinces). Elle gomme ainsi en partie les variations des conditions réelles rencontrées par les personnes. Faute de mieux, c'est ce maillage géographique que nous utiliserons pour rendre compte des covariations spatiales entre indicateurs du chômage, d'une part, et de certains phénomènes susceptibles d'agir sur lui, d'autre part ${ }^{21}$.

\section{Neutralité de la démographie}

17 La démographie est-elle source de chômage ? Parce qu'il serait devenu trop rapide, le rythme d'accroissement de la population d'âge actif dépasserait les capacités de 
création d'emploi d'une économie insuffisamment dynamique ; le phénomène serait en outre amplifié dans les villes par l'exode rural. Cette thèse d'inspiration malthusienne, voyant l'emploi comme une quantité limitée et la démographie comme un facteur qui aiguise la concurrence pour y accéder, est très répandue en Égypte ${ }^{22}$. Elle n'aide cependant pas à comprendre l'évolution du chômage. Si la montée du chômage répondait simplement à la croissance démographique, comment expliquer qu'un siècle durant, la population se soit accrue sans provoquer une hausse particulière du chômage? Que cette dernière hausse survienne précisément au moment où s'annonce un ralentissement de l'accroissement démographique ${ }^{23}$ ? Qu'elle soit postérieure à la grande période de l'exode rural (1930-1970)?

La thèse malthusienne n'aide pas mieux à comprendre la répartition inégale du chômage dans le pays. Remarquable est en effet l'absence de corrélation entre la plupart des indicateurs de la dynamique démographique d'une part, et de la dynamique du chômage, d'autre part $^{24}$. Mieux encore, les rares corrélations significatives sont négatives. On observe ainsi que le chômage rural d'après le recensement de 1996 est en corrélation négative $(-0,66)$ avec la croissance de la population rurale entre les deux recensements de 1986 et 1996. Faut-il lire dans cette relation insolite, de direction opposée à l'attente malthusienne, un effet direct du chômage sur la croissance démographique des campagnes, un fort chômage rural alimentant alors l'émigration? Sans doute non car, en considérant la croissance démographique totale, villes et campagnes ensemble, la corrélation avec le chômage rural est tout aussi négative ($0,68)$ : si le chômage rural motive l'exode rural, celui-ci ne prend en tout cas pas la forme d'une émigration de proximité vers la capitale de la muhâfadha. Il s'agit donc plutôt d'une relation indirecte : le chômage accompagne l'élévation du niveau éducatif, elle-même liée à la baisse de la natalité, c'est-à-dire à une croissance démographique plus faible. Cette hypothèse est confortée par une autre corrélation négative, entre taux de chômage urbain et croissance de la population rurale aux âges actifs $(-0,62)$. Plus les campagnes ont une croissance démographique élevée, statistiquement liée à une instruction scolaire plus courte, moins elles alimentent les villes en chômeurs. Les facteurs qui expliquent la montée du chômage seraient ainsi les mêmes que ceux qui expliquent la modération de la croissance démographique.

\section{Chômage et pauvreté}

La montée du chômage est contemporaine d'une détérioration des conditions de vie pour une partie importante de la population égyptienne, en particulier la plus défavorisée. Non seulement la masse des pauvres s'est accrue depuis le début des années quatre-vingt, mais les inégalités de revenu se sont creusées et les polarités aiguisées: la situation des pauvres s'est détériorée tandis que celle des autres s'est plutôt améliorée ${ }^{25}$. Ces faits sont suffisamment bien établis par une série d'études ${ }^{26}$ pour que nous n'y revenions pas. Que chômage et pauvreté soient liés de multiples façons ne fait par ailleurs pas de doute. Ils le sont d'abord dans toutes les situations individuelles où les conditions d'existence se trouvent détériorées par la privation de revenu du travail qu'occasionne l'état de chômeur. Ils sont aussi liés par un même rapport aux évolutions macro-économiques: l'abandon par l'État de toutes sortes de subventions à la consommation des ménages, l'érosion de son rôle de pourvoyeur d'emploi, la tendance du capital privé à se fixer sur des activités faiblement créatrices 
d'emploi et la faiblesse de l'intervention publique dans la redistribution des revenus sont autant de faces d'une même politique de réforme économique.

La multiplicité des liaisons fonctionnelles entre les deux phénomènes n'entraîne cependant pas qu'un contexte local de pauvreté soit le plus favorable au chômage, ni, inversement, qu'un revenu moyen plus élevé soit favorable à l'emploi. Entre les indices de la pauvreté et de la pauvreté extrême et ceux du chômage, on n'observe aucune corrélation significative. L'explication peut résider dans les situations individuelles elles-mêmes: le chômage serait un état qui suppose un minimum de ressources, d'origine familiale par exemple. Les plus pauvres ne pourraient donc pas l'affronter et se trouveraient contraints d'accepter n'importe quelle situation de sous-emploi; le chômage absolu ne serait accessible qu'aux classes moyennes. Si les statistiques du travail restituaient la gradation qui existe dans le temps de travail effectif ou dans la productivité, sans doute révéleraient-elles que la pauvreté va de pair avec le sousemploi, parce que celui-ci ne procure que de très faibles revenus ${ }^{27}$.

L'absence de corrélation entre le chômage et la pauvreté peut cependant aussi bien trouver son origine dans les situations collectives. Le chômage apparait en effet comme fortement lié à des facteurs qui caractérisent les régions où la pauvreté est moindre. C'est ainsi que l'instruction scolaire présente une géographie opposée à celle de la pauvreté, mais voisine de celle du chômage. Que l'on considère les niveaux actuels, les changements récents ou les évolutions plus longues, les indicateurs d'éducation sont corrélés négativement avec la proportion de population vivant au-dessous du seuil de pauvreté et positivement avec les indices de chômage ${ }^{28}$. Cette dernière relation est d'ailleurs antérieure à la poussée récente du chômage, puisqu'on la trouve dès 1962, époque du plein emploi : bien qu'il soit alors résiduel, le chômage possède déjà une géographie bien tranchée, la même que le niveau éducatif ${ }^{29}$. Comme l'instruction scolaire, l'indice de développement humain qui combine santé, éducation et revenu moyen est en corrélation positive avec le chômage ${ }^{30}$. On pourrait multiplier les exemples de ces liaisons statistiques en partie redondantes. Toutes expriment un même état de fait paradoxal : la montée du chômage est partie intégrante d'un ensemble de transformations sociales et économiques qui sont par ailleurs considérées comme autant de signes de croissance, sinon de développement.

\section{Structure des activités économiques}

Parmi ces transformations, la modification de la répartition des activités entre les grands secteurs économiques - tassement de la population agricole au profit de l'industrie et des services - est peut-être la plus susceptible d'entretenir une relation directe avec cette autre facette de l'activité qu'est le chômage.

La place de l'agriculture varie beaucoup selon les muhâfadhât, dont elle forme (1995) entre 11,9 \% des actifs (Isma'îliyya) et 56,1 \% (Minyâ) ${ }^{31}$, de même que son évolution sur le moyen terme, avec une perte entre 1962 et 1995 comprise entre - 20,2 points (Minyâ) et - 46,1 (Aswân). Ces variations éclairent-elles celles du chômage ? À première vue, non. Ni dans une perspective statique, ni dans une perspective dynamique, la part de l'agriculture dans les activités n'explique statistiquement les variations régionales du chômage. On observe bien quelques corrélations très négatives, mais autant de corrélations non significatives. Par exemple, si le chômage féminin à 20-24 ans varie en raison inverse de la place que l'agriculture conserve, ce qui parait accréditer l'idée d'un 
phénomène d'accompagnement de la désaffection de l'agriculture ${ }^{32}$, il n'en va pas de même lorsque l'on considère les hommes: le niveau du chômage masculin semble indifférent à la part des activités agricoles. Les créations nettes d'emplois parmi les jeunes $^{33}$ ne présentent pas non plus de lien statistique avec l'évolution de la population agricole. L'indépendance relative du chômage par rapport à l'importance et à la dynamique du secteur agricole vient de ce qu'il ne touche à peu près pas ce secteur luimême ${ }^{34}$, où seul le sous-emploi est une réalité massive. Cela ne veut pas dire que le volume du chômage soit sans rapport avec l'agriculture, mais qu'il exprime plutôt son faible pouvoir d'absorption des nouvelles qualifications que présentent les jeunes générations. La différence entre les régions tient entièrement à la part respective des deux autres secteurs, industrie et artisanat de production d'un côté, commerce, services et administration de l'autre.

Le développement de l'industrie semble contenir la poussée du chômage. Celui-ci se fixe en effet là où l'industrie occupe peu de place et progresse lentement. C'est ce qu'indiquent ensemble les corrélations fortement négatives de la plupart des indicateurs du chômage avec la proportion de population active dans l'industrie variant de 5,5\% à Kafr al-Shaykh à 35,3\% à Dumyât et 39,4\% à Alexandrie (1995) - et avec sa progression sur le moyen terme (1962-1995) - qui va d'une perte de - 3,3 points à Port-Sa'îd et $-3,1$ à Aswân à un gain de $+14,7$ à Gîza et $+16,6$ à Dumyât ${ }^{35}$. Plus remarquable est la dilution des particularités régionales, notamment des contrastes entre delta et vallée que toutes sortes d'autres indicateurs attestent, lorsque l'on considère la relation qui lie le chômage à la faiblesse de l'industrie. Dans l'étagement des muhâfadhât, on trouve ainsi, côte à côte, Kafr al-Shaykh et Minyâ, Qinâ et Daqahliyya, ou encore Le Caire et Dumyât (graphique 6). Peut-être est-ce le signe d'une relation directe, affranchie des autres conditions locales, comme si c'était l'emploi industriel lui-même qui prévenait le chômage. L'emploi industriel doit ici s'entendre dans un sens large, incluant aussi bien les usines conçues par l'État providence des années soixante comme "des organismes de services, devant offrir au public des bénéfices sociaux sous forme d'emploi et de bas prix» (Harik, 1997, p. 41), que les petites unités de production privée qui recueillent aujourd'hui toutes les faveurs des organisations financières internationales et des institutions locales œuvrant à la redistribution des ressources, dont l'emploi fait partie, par une promotion de la petite entreprise et de l'initiative privée ${ }^{36}$.

En vertu d'une arithmétique élémentaire - la complémentarité numérique de l'industrie et des services dans les activités non agricoles -, la corrélation change de signe, mais non d'intensité, lorsque l'on substitue les services à l'industrie ${ }^{37}$. Le chômage est directement proportionnel au développement des services. En passant, on notera que la corrélation positive relevée plus haut entre le revenu moyen (en fait, le $\mathrm{PNB} /$ hab.) et le chômage trouve ici son explication: ce n'est pas l'industrie, en effet, qui procure les revenus les plus élevés aux personnes, mais les services ${ }^{38}$. Dans le milieu rural, l'association du chômage et des services est particulièrement significative : si l'on classe les muhâfadhàt selon le double critère du taux de chômage et de l'augmentation de la part des services au cours des trois dernières décennies, on obtient un alignement presque parfait (graphique 7). Depuis Gizâ, qui combine les minima, jusqu'à Aswân, qui détient le double record du chômage et de la croissance des activités de services, chômage et activités de services marchent du même pas. Pas plus qu'avec l'industrie, l'alignement des muhâfadhât nerespecte ici les proximités géographiques: sur le chemin de Gizâ à Aswân, on trouve Isma'îliyya et Dumyât dans des situations 
identiques, un peu plus loin Qinâ et Buhayra, encore plus loin Daqahliyya et Asyût. Ce mélange des lieux semble désigner des facteurs généraux, comme si chômeurs et employés des services se recrutaient parmi les mêmes profils, quelle que soit la région. L'instruction scolaire est un élément central de ce profil: de même que le diplôme caractérisait une majorité des chômeurs, un niveau d'éducation supérieur à la moyenne distingue les employés des services ${ }^{39}$.

Parce qu'il est extrême, le cas de la muhâfadha d'Aswân résume le faisceau des facteurs qui installent le chômage : première région par tous les indicateurs du chômage, elle l'est aussi par la progression de l'éducation masculine et vient au second rang par l'importance des services, juste derrière Port-Sa'îd, un gouvernorat exclusivement urbain ; la faiblesse de son activité industrielle la place par ailleurs en avant-dernière position. Cette position limite résulte d'une histoire économique unique, celle du plus grand chantier de l'Égypte contemporaine. La construction du haut barrage dans les années soixante a bouleversé la structure des activités, avec un boom du secteur industriel qui resta temporaire, limité aux travaux du chantier lui-même ${ }^{40}$ et fut relayé, non par l'installation d'industries créatrices d'emploi, mais par l'expansion rapide de l'administration, dont l'appareil scolaire, du commerce et de tous les services induits par une situation stratégique. C'est bel et bien dans une histoire locale que se joue la montée du chômage.

Le binôme que forment le chômage et les activités de services n'est pas nouveau. Il était déjà là en 1962, âge d'or du plein emploi de l'économie dirigiste ${ }^{41}$. Durant les trente années suivantes la géographie du chômage a certes changée ${ }^{42}$, mais non les relations entre le chômage et ses facteurs, insensibles au formidable changement d'échelle du phénomène. Alors qu'il n'avait encore qu'une dimension résiduelle, le chômage s'inscrivait déjà dans la même configuration qu'aujourd'hui. Le passage à l'économie de marché et la croissance des corrélats du chômage, instruction et services, n'ont pas altéré une relation qui existait déjà ; ils l'ont simplement rendue plus manifeste. Par delà la succession des options d'économie politique, le chômage a conservé intactes ses caractéristiques structurelles. Seul son niveau a changé.

\section{Conclusion}

Défini par opposition stricte au travail, le chômage n'est qu'une position limite dans toute la gamme des situations qui vont de l'inactivité complète au plein emploi des capacités de l'individu. Sans doute n'est-elle pas la plus visible pour qui observe la masse des personnes occupées seulement par intermittence ou affairées avec continuité à des activités aussi peu productives que rémunératrices. Elle est en tous cas la seule lisible au moyen de la statistique, telle qu'elle est construite et accumulée par l'administration égyptienne. Le chômage statistique, taillé comme toute catégorie dans un continuum, s'inscrit toutefois suffisamment bien dans un faisceau de configurations et d'évolutions sociales et économiques pour y voir le reflet d'une transformation réelle du travail. Celle-ci toucherait à la fois les conditions objectives de l'exercice du travail, lui-même soumis aux lois de l'économie de marché qui s'installe, et les représentations du travail. Sont en effet consignés comme chômeurs ceux qui déclarent chercher un emploi et n'en avoir pas trouvé, c'est-à-dire des personnes qui ont conscience d'être exclues du travail, que leur exclusion vécue réponde ou non aux normes du statisticien. 
La conception dichotomique du travail ferait ainsi son chemin dans la population ellemême, et non seulement dans la statistique.

L'exclusion du travail est favorisée par certains contextes plus que par d'autres. Elle épouse notamment les contours de la tertiairisation de l'économie. Corrélative de la tertiairisation, l'institution scolaire fabrique aussi bien ceux qui serviront l'économie de services que ceux qui en seront exclus. Les jeunes diplômés sont les premiers, voire les seuls touchés par le chômage. La montée de l'instruction scolaire et celle du chômage agissent ainsi de concert pour accentuer les clivages verticaux dans la population, entre jeunes et vieux. L'instruction, plus répandue parmi les premiers, leur donne sur leurs aînés un avantage dans l'ordre symbolique, mais le chômage les prive d'en tirer les bénéfices dans l'ordre matériel. Cette combinaison défavorable pourrait nourrir une tension entre les générations. Pour les jeunes femmes, dont une majorité conclura la recherche d'un emploi par le renoncement au travail, à la pénalisation de l'âge s'ajoute celle du sexe. Avec pour cible des positions moyennes dans la société, celles des familles qui amènent leurs enfants jusqu'à la fin d'une scolarité secondaire, le chômage pourrait n'opposer pas tant des classes sociales entre elles que des groupes plus primaires, déterminés par les distinctions élémentaires de l'âge et du sexe.

\section{BIBLIOGRAPHIE}

\section{Sources}

CAPMAS, Bahth al-'imâla bi-l-'ayyina (Enquête par échantillon sur la main-d'œuvre) : volumes de 1962, 1963, 1964, 1968, 1969, 1970, 1971, 1972, 1973, 1973, 1974, 1975, 1977, 1978, 1979, 1980, 1981 , 1982, 1983, 1984, 1988, 1990, 1990, 1991, 1992, 1993, 1995.

CAPMAS, Al-tïdâd al-'amm li-l-sukkân wa-l-iskân (Recensement général de la population et de l'habitat) : 1966,1976,1986,1996 (résultats globaux préliminaires).

CAPMAS, Bahth al-infâq wa-l-istihlâk. 'ayyina min al-usar al-misriyya. 1995/96 (Enquête par échantillon sur les dépenses et la consommation des ménages), Le Caire, 1997.

\section{Études citées}

AL-KHAWÂGA Leïla A., 1989, Dirâsa tahliliyya li-dhâhirat al-bitâla al-sâfira wa 'ilâqatuha bihaykalsûq a/-'ama/fî̀ Msr(Analyse du chômage et de sa relation avec la structure du marché du travail en Égypte), dans SULEIMAN (1989).

AL-TAHÂWI Mona, 1989, Tahlîl Dhâhirat al-bitâla bayn al-muta'allimîn fî Misr (Analyse du phénomène de chômage parmi la population éduquée en Egypte), dans SULEIMAN (1989).

ASSAAD Ragui, 1989, Naqs al-tashghil wa tajazzu' sûq al-'amal fî Misr (Pénurie d'emploi et segmentation du marché du travail en Égypte), dans SULEIMAN (1989). 
ASSAAD Ragui, MALAK Rouchdy, 1998, Poverty and Poverty Alleviation Strategies in Egypt, Cairo, The Ford Foundation.

EL EMARY Ahmed Souelem, 1937, « La structure économique de l'Égypte », L'Égypte Contemporaine, vol. 28.

EZZ AL-ARAB Mustapha Muhammad, 1989, « Mustaqbal shakl al-bitâla fi Misr, fi daw'almutaghayyirâtal-mahaliyya, al-iqlîmiyya, al-'âlamiyya (L'avenir du chômage en Égypte, à la lumière des variables locales, régionales, mondiales) ", dans Société d'Économie Politique, de Statistique et de Législation, XlVe Congrès annuel des économistes égyptiens, Le Caire.

FARAG Iman, Enjeux et trajectoires de l'éducation en Égypte, thèse de doctorat en cours, EHESS, Paris.

FARGUES Philippe, 1997, « State Policies and the Birth Rate in Egypt : from Socialism to Liberalism ", Population and Development Review, New York, 23/1, p. 115-138.

FERGANY Nader :

- 1990, Employment and Unemployment in the Domestic Economy, CAPMAS Labour Information System Project, Preliminary Report I/1, December.

- 1991, «A characterisation of the Employment Problem in Egypt », in Handoussa and Potter (1991).

- 1997a, Dynamics of Employment Creation and Destruction. Egypt, 1990-1995, Cairo, Al-Miskat.

- 1997b, Unemployment and Poverty in Egypt, Cairo, Al-Miskat.

HANDOUSSA Heba «Crisis and Challenge : Prospects for the 1990s », in Handoussa and Potter (1991).

HANDOUSSA Heba, Gillian POTTER (éd.), 1991, Employment and Structural Adjustment in Egypt in the 1990s, Cairo, The AUC Press.

HARIK llya, 1997, Ecomic Policy Reform in Égypt, University Press of Florida.

HUSAYNAdel, 1982, Al-iqtisâd al-misri min al-istiqlâl ilâ-l-tab'iyya, 1974-1979 (L'économie égyptienne de l'indépendance à la dépendance), Le Caire, Dâr al-mustaqbal al-'arabî.

JOLIFFE Dean, 1997, What Do We Know about Poverty in Egypt? An Analysis of-Household Survey Data for 1997, S. Francisco, Middle East Studies Association, 31 st meeting.

KARSHENAS Massoud, 1997, « Economic Liberalization, Competitiveness and Women's Employment in the Middle East and North Africa », Working Paper 9705, Cairo, Economic Research Forum.

MÉDA Dominique, 1995, Le travail, une valeur en voie de disparition, Paris, Aubier.

MOHIE EL-DIN Amr, 1977, Open Unemployment in the Egyptian Economy, The Institute of National Planning, Cairo.

NASSEF Abdel Fattah (ed), 1997, Egypt Human Development Report 1996, Cairo, The Institute of National Planning.

ROSANVALLON Pierre, 1995, La nouvelle question sociale, Paris, Seuil.

SABRÎ ABDALLAH Isma'îl, 1989, Al-Khasâ'is al-mushtaraka fî Dhâhirat al-bitâla fi buldân al-'âlam althâlith ma' 'ishâra khâssa li-Misr (Les caractéristiques associées au phénomène du chômage dans les pays du tiers-monde, en Égypte notamment), dans Suleiman (1989).

SHAMI Seteney (éd.), 1990, Women in Arab Society, Work Patterns and Gender Relations in Egypt, Jordan and Syria, Paris, Unesco. 
SHENOUDA Shenouda Samaan, 1991, Al-bitâla fî Misr, dirâsa tahlîliyya (Le chômage en Egypte, essai d'analyse), Cairo, The Institute of National Planning.

SULEIMAN Salwa (dir.),1989, Colloque Al-Bitâla il Misr (le chômage en Égypte), Université du Caire. TOPALOV Christian, 1994, Naissance du chômeur. 1880-1910, Paris, Albin Michel.

WAHDÂN Nâdira, 1991, Ta'thîr al-bitâla 'alâ ziyâdat mu'addalât al-jarîma fi Misr (Influence du chômage sur l'augmentation de la criminalité en Égypte), Cairo, The Institute of National Planning.

\section{ANNEXES}

Tableau 1 : Indicateurs de chômage, Égypte entière, 1962-1995

\begin{tabular}{|l|c|c|c|c|c|c}
\hline Année & \multicolumn{3}{c}{ Taux de chômage (p. 100 actifs) } & $\begin{array}{c}\text { Proportion de } \\
\text { femmes }\end{array}$ & $\begin{array}{c}\text { Demandeurs 1er } \\
\text { emploi }\end{array}$ \\
\hline & Hommes & Femmes & Ensemble & \multicolumn{2}{c}{ (pour 100 chômeurs des 2 sexes) } \\
\hline 1962 & 2.2 & 2.0 & 2.2 & 5.9 & - \\
\hline 1963 & 3.2 & 2.4 & 3.2 & 6.6 & - \\
\hline 1964 & 1.9 & 1.3 & 1.9 & 4.8 & \\
\hline 1968 & 3.0 & 4.2 & 3.1 & 11.0 & \\
\hline 1969 & 2.5 & 4.9 & 2.7 & 12.0 & \\
\hline 1970 & 2.1 & 6.0 & 2.4 & 16.7 & - \\
\hline 1971 & 1.5 & 6.2 & 1.8 & 23.2 & 77.9 \\
\hline 1972 & 1.2 & 5.3 & 1.5 & 23.9 & 77.3 \\
\hline 1973 & 1.3 & 7.5 & 1.6 & 26.6 & 84.6 \\
\hline 1974 & 1.9 & 11.7 & 2.6 & 32.1 & 86.1 \\
\hline 1975 & 1.7 & 13.2 & 2.5 & 35.9 & 89.9 \\
\hline 1977 & 2.4 & 12.1 & 3.1 & 29.1 & 89.4 \\
\hline 1978 & 2.7 & 13.4 & 3.6 & 32.5 & 84.9 \\
\hline
\end{tabular}




\begin{tabular}{|l|c|c|c|c|c|}
\hline Année & \multicolumn{3}{|c|}{ Taux de chômage (p. 100 actifs) } & $\begin{array}{c}\text { Proportion de } \\
\text { femmes }\end{array}$ & $\begin{array}{c}\text { Demandeurs 1er } \\
\text { emploi }\end{array}$ \\
\hline & Hommes & Femmes & Ensemble & (pour 100 chômeurs des 2 sexes) \\
\hline 1979 & 3.4 & 18.2 & 4.6 & 30.9 & 92.6 \\
\hline 1980 & 3.9 & 19.2 & 5.2 & 30.8 & 90.7 \\
\hline 1981 & 4.1 & 18.8 & 5.4 & 31.4 & 94.0 \\
\hline 1982 & 4.1 & 20.5 & 5.7 & 33.9 & 94.2 \\
\hline 1983 & 5.7 & 10.6 & 6.5 & 28.3 & 90.7 \\
\hline 1984 & 4.8 & 15.7 & 6.8 & 43.1 & 93.7 \\
\hline 1988 & 5.5 & 10.3 & 7.2 & 51.1 & 91.7 \\
\hline 1990 & 5.6 & 14.4 & 8.0 & 49.7 & 89.8 \\
\hline 1991 & 6.5 & 15.6 & 8.8 & 45.0 & 91.4 \\
\hline 1992 & 6.4 & 17.0 & 9.0 & 45.7 & 94.4 \\
\hline 1993 & 7.5 & 23.1 & 11.1 & 48.8 & 95.2 \\
\hline 1994 & 7.5 & 22.3 & 10.9 & 46.9 & 94.8 \\
\hline 1995 & 7.5 & 24.1 & 11.3 & 48.1 & 95.6 \\
\hline
\end{tabular}

Source : CAPMAS, enquête annuelle sur l'emploi.

Tableau 2 : Répartition du chômage selon l'âge et le sexe en 1995

\begin{tabular}{|l|c|c|c|c|c|}
\hline Groupe d'âges & \multicolumn{3}{|c|}{ Taux de chômage (p. 100 actifs) } & \multicolumn{3}{c|}{ Répartition de 100 chômeurs des 2 sexes } \\
\hline & Hommes & Femmes & Hommes & Femmes & Total \\
\hline $15-19$ & 16.0 & 58.6 & 9.8 & 11.4 & 21.2 \\
\hline $20-24$ & 31.0 & 59.2 & 24.9 & 22.6 & 47.5 \\
\hline $25-29$ & 15.3 & 35.3 & 13.8 & 12.0 & 25.8 \\
\hline $30-39$ & 1.7 & 3.9 & 2.9 & 2.1 & 5.1 \\
\hline $40-49$ & 0.2 & 0.1 & 0.3 & 0.0 & 0.4 \\
\hline $50-59$ & 0.1 & 0.1 & 0.1 & 0.0 & 0.1 \\
\hline $60-64$ & 0.2 & 0.0 & 0.0 & 0.0 & 0.0 \\
\hline Total & 7.5 & 24.1 & 51.9 & 48.1 & 100.0 \\
\hline
\end{tabular}

Source : CAPMAS, enquête sur l'emploi 1995. 
Tableau 3 : Taux de chômage selon le niveau d'éducation le sexe et le milieu de résidence, 1990 et 1995

\begin{tabular}{|c|c|c|c|c|c|c|}
\hline \multirow{2}{*}{$\begin{array}{l}\text { Niveau } \\
\text { d'éducation }\end{array}$} & \multicolumn{3}{|c|}{ Hommes } & \multicolumn{3}{|c|}{ Femmes } \\
\hline & 1990 & 1995 & Différence & 1990 & 1995 & Différence \\
\hline & \multicolumn{6}{|c|}{ Milieu urbain } \\
\hline Analphabète & 1.3 & 1.3 & 0.0 & 7.4 & 1.4 & -6.0 \\
\hline Lit et écrit & 1.2 & 0.7 & -0.5 & 9.1 & 2.7 & -6.4 \\
\hline Primaire & 6.1 & 2.9 & -3.2 & 24.7 & 13.6 & -11.2 \\
\hline Secondaire & 15.8 & 18.3 & 2.5 & 34.6 & 41.2 & 6.6 \\
\hline $\begin{array}{l}\text { Supérieur } \\
\text { incomplet }\end{array}$ & 17.4 & 17.2 & -0.2 & 28.4 & 24.0 & -4.4 \\
\hline Universitaire & 10.1 & 7.6 & -2.5 & 20.2 & 15.7 & -4.5 \\
\hline \multirow[t]{2}{*}{ Total } & 6.9 & 7.6 & 0.7 & 24.6 & 27.6 & 3.0 \\
\hline & \multicolumn{6}{|c|}{ Milieu rural } \\
\hline Analphabète & 0.1 & 0.2 & 0.1 & 1.3 & 0.0 & -1.2 \\
\hline Lit et écrit & 0.7 & 0.4 & -0.3 & 2.8 & 1.6 & -1.2 \\
\hline Primaire & 4.6 & 1.3 & -3.3 & $20.4^{*}$ & 7.2 & .13 .2 \\
\hline Secondaire & 22.5 & 30.2 & 7.7 & 54.6 & 65.6 & 10.9 \\
\hline $\begin{array}{l}\text { Supérieur } \\
\text { incomplet }\end{array}$ & 18.3 & 15.5 & -2.8 & 22.1 & 26.9 & 4.9 \\
\hline Universitaire & 16.8 & 16.0 & -0.8 & 25.3 & 28.0 & 2.7 \\
\hline Total & 4.6 & 7.5 & 2.9 & 8.8 & 21.4 & 12.6 \\
\hline
\end{tabular}

Source : CAPMAS, enquête sur l'emploi, 1990 et 1995

Tableau 4 : Répartition des chômeurs selon le niveau d'éducation, le sexe et le milieu de résidence en 1995 (effectifs en milliers)

\begin{tabular}{|l|c|c|c|c|c|c|c|}
\hline Niveau & \multicolumn{2}{|c|}{ Milieu rural } & \multicolumn{2}{c|}{ Milieu urbain } & \multicolumn{2}{c|}{ Égypte entière } & Total \\
\hline d'éducation & Hommes & Femmes & Hommes & Femmes & Hommes & Femmes & \\
\hline Analphabète & 13.0 & 1.4 & 7.9 & 0.5 & 20.9 & 1.9 & 22.8 \\
\hline Lit et écrit & 10.5 & 1.6 & 7.0 & 1.1 & 17.5 & 2.7 & 20.2 \\
\hline Primaire & 15.1 & 5.3 & 4.8 & 2.2 & 19.9 & 7.5 & 27.4 \\
\hline Secondaire & 275.9 & 328.4 & 428.3 & 417.7 & 704.2 & 746.1 & 1450.3 \\
\hline $\begin{array}{l}\text { Supérieur } \\
\text { incomplet }\end{array}$ & 50.3 & 45.0 & 34.2 & 23.7 & 84.5 & 68.7 & 153.2 \\
\hline Universitaire & 84.1 & 70.6 & 60.0 & 21.7 & 144.1 & 92.3 & 236.4 \\
\hline Total & 448.9 & 452.3 & 542.2 & 466.9 & 991.1 & 919.2 & 1910.3 \\
\hline
\end{tabular}

Source : CAPMAS, enquête sur l'emploi, 1995. 
Tableau 5 : Dépenses moyennes par personne, selon le type d'activité du chef de ménage, Égypte entière, 1995-1996 (livres/an)

\begin{tabular}{|l|c|c|c|c|c|}
\hline & \multicolumn{5}{|c|}{ Chômeurs } \\
\hline & Occupés & $\begin{array}{c}\text { N'ayant jamais de dépense } \\
\text { travaillé }\end{array}$ & $\begin{array}{c}\text { Ayant déjà } \\
\text { travaillé }\end{array}$ & Inactís & Ensemble \\
\hline Toutes dépenses & 1772 & 1587 & 1012 & 1875 & 1793 \\
\hline Nouriture & 793 & 812 & 536 & 906 & 819 \\
\hline Vêtements & 171 & 128 & 109 & 168 & 170 \\
\hline Logement & 159 & 241 & 96 & 175 & 163 \\
\hline Proportion de familles & 76.4 & 0.1 & 0.3 & 23.2 & 100.0 \\
\hline
\end{tabular}

Source : CAPMAS, enquête sur les dépenses et la consommation, 1995-1996.

Graphique 1 : Taux de chômage selon le sexe, Égypte entière (1962-1996)

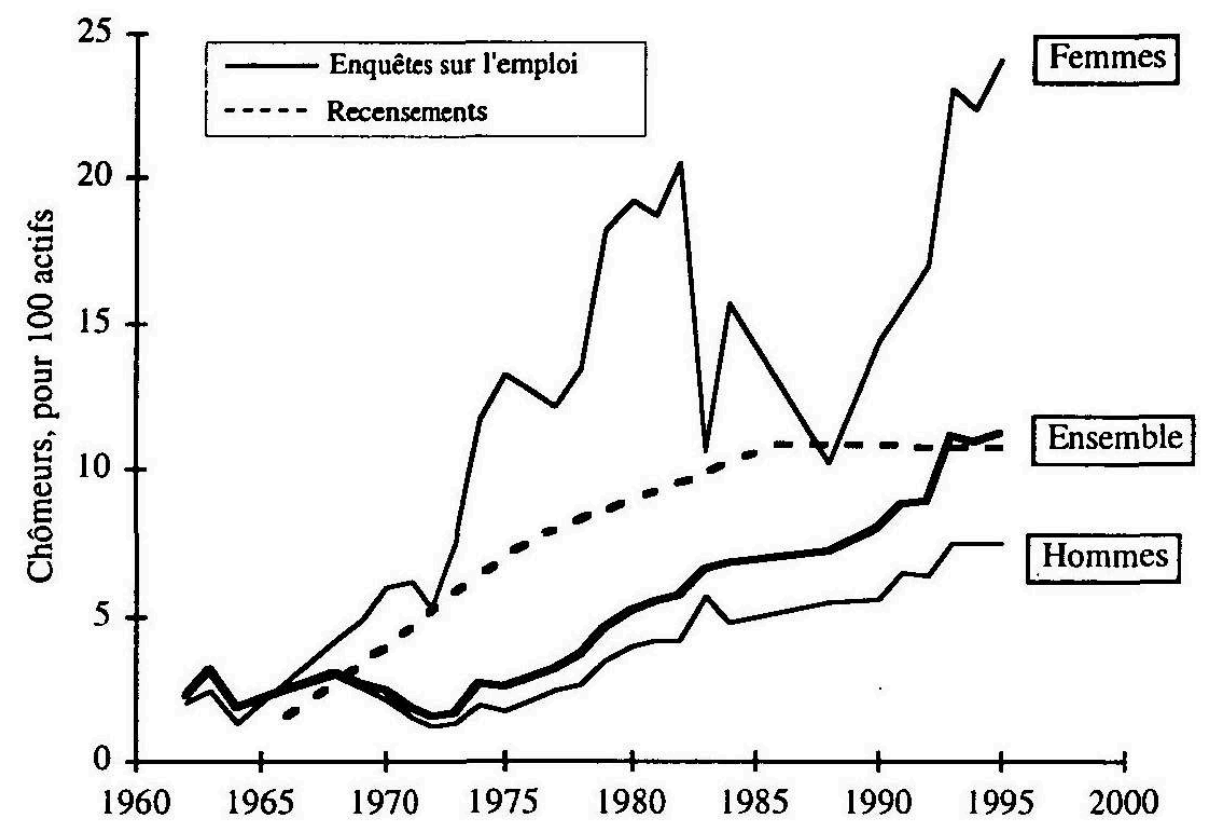


Graphique 2 : Proportion de femmes parmi les chômeurs, 1962-1995

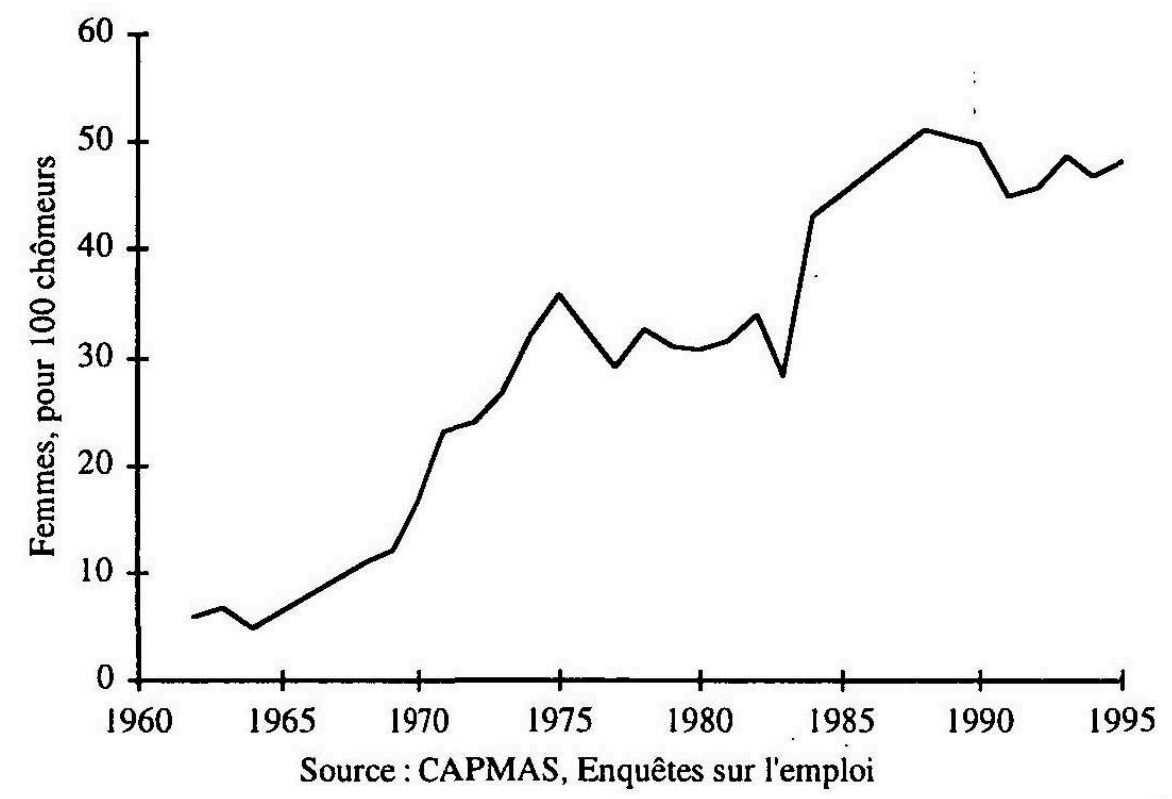

Graphique 3A : Évolution de la structure d'activité dans les générations entre 1990 et 1995

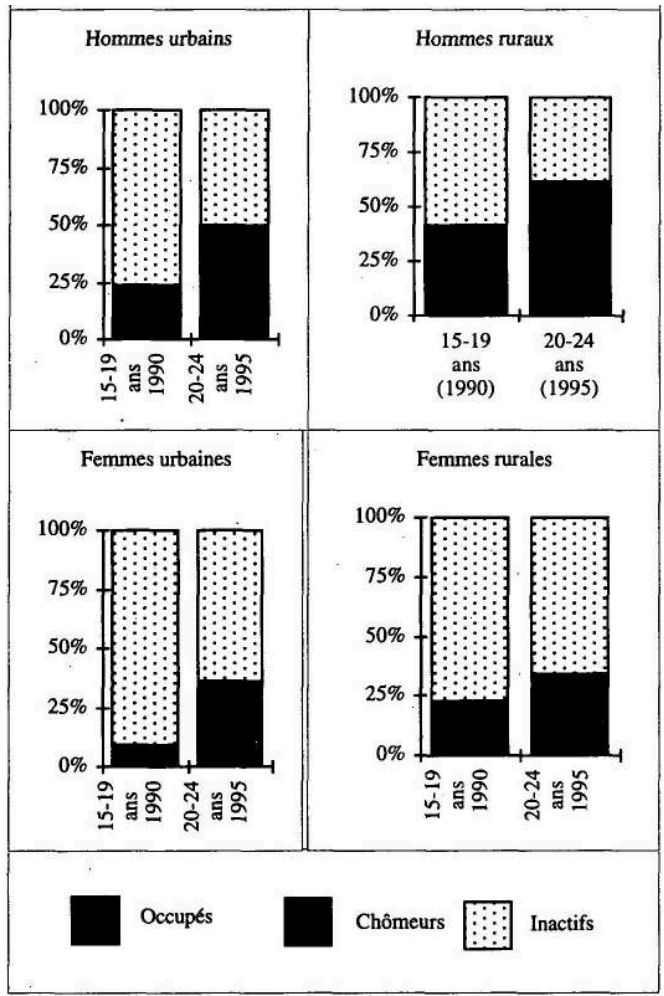


Graphique 3B : Évolution de la structure d'activité dans les générations entre 1990 et 1995

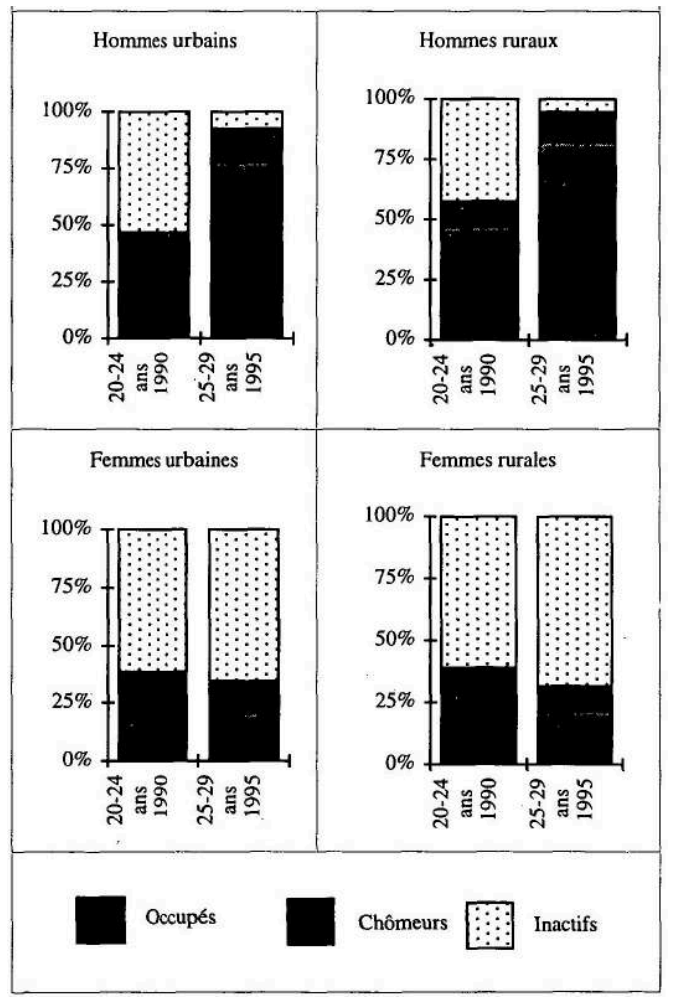

Graphique 4 : Gains et pertes de population active dans les générations 1966-1970 entre 1990 et 1995

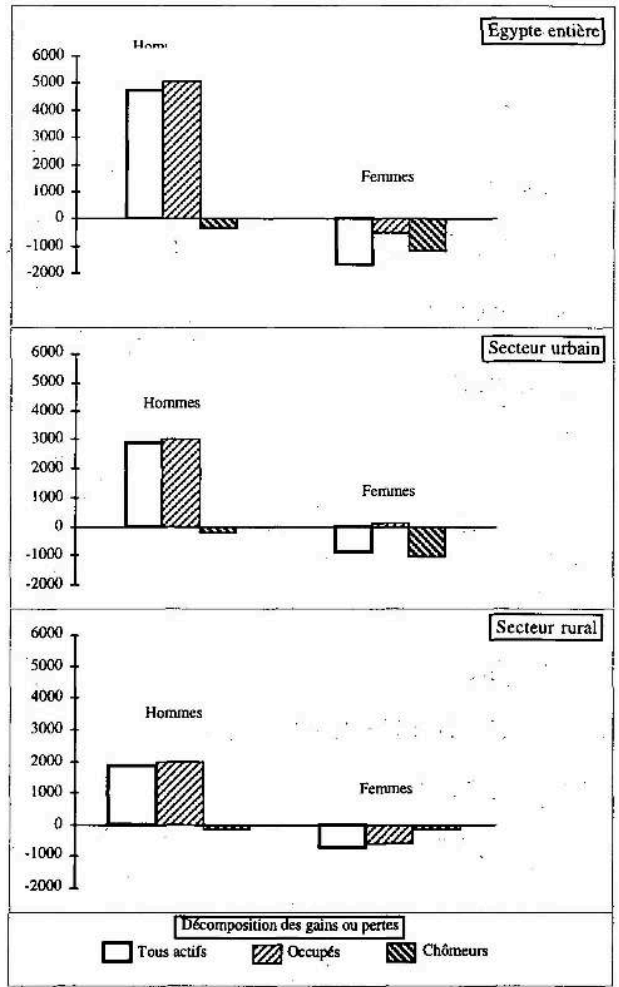


Graphique 5 : Taux de chômage (p.100 actifs) selon le sexe et le niveau d'éducation - 1964 et 1995

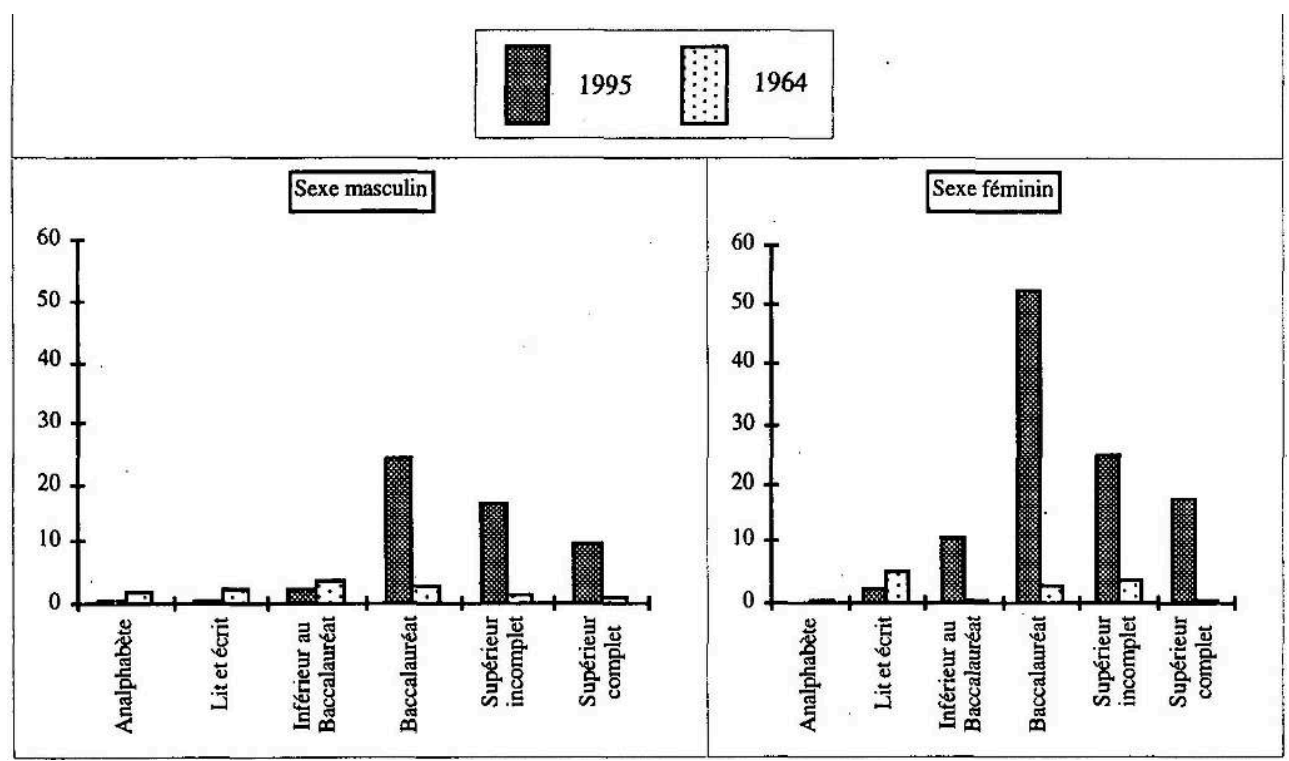

Graphique 6 : Progression du chômage masculin urbain entre 1962 et 1995 et place de l'industrie en 1995

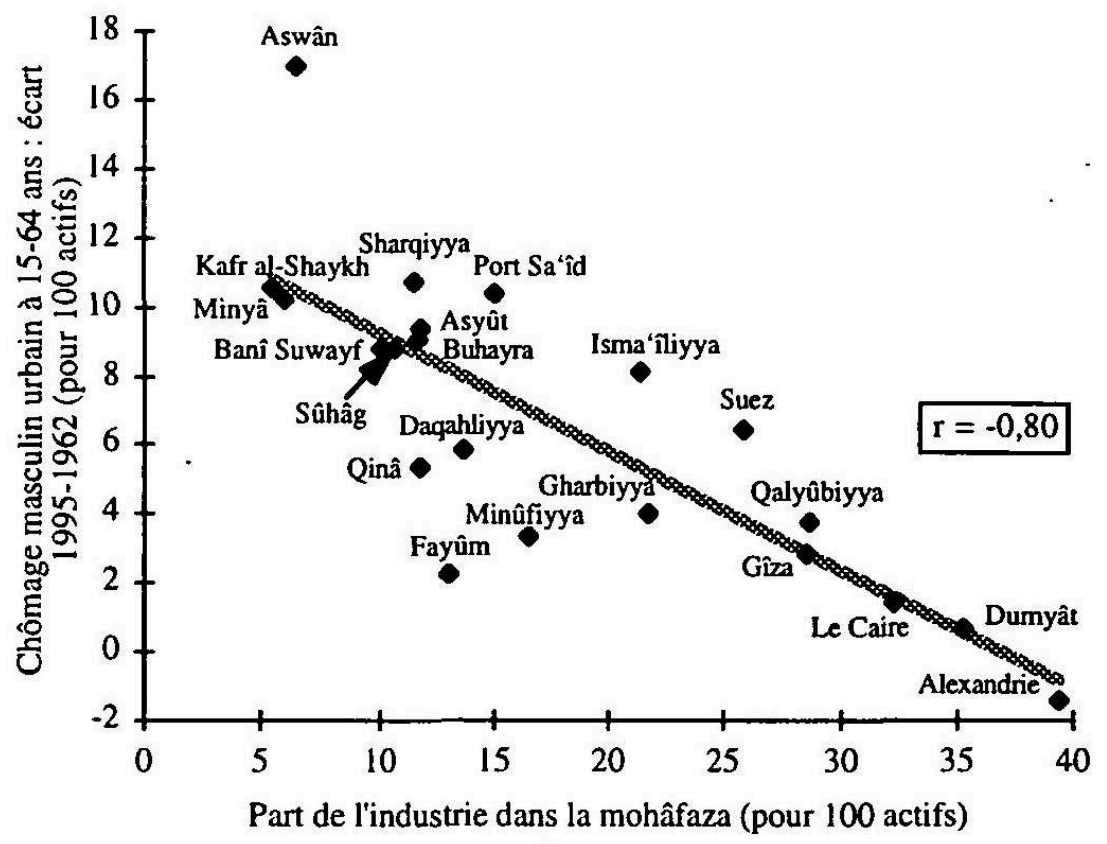




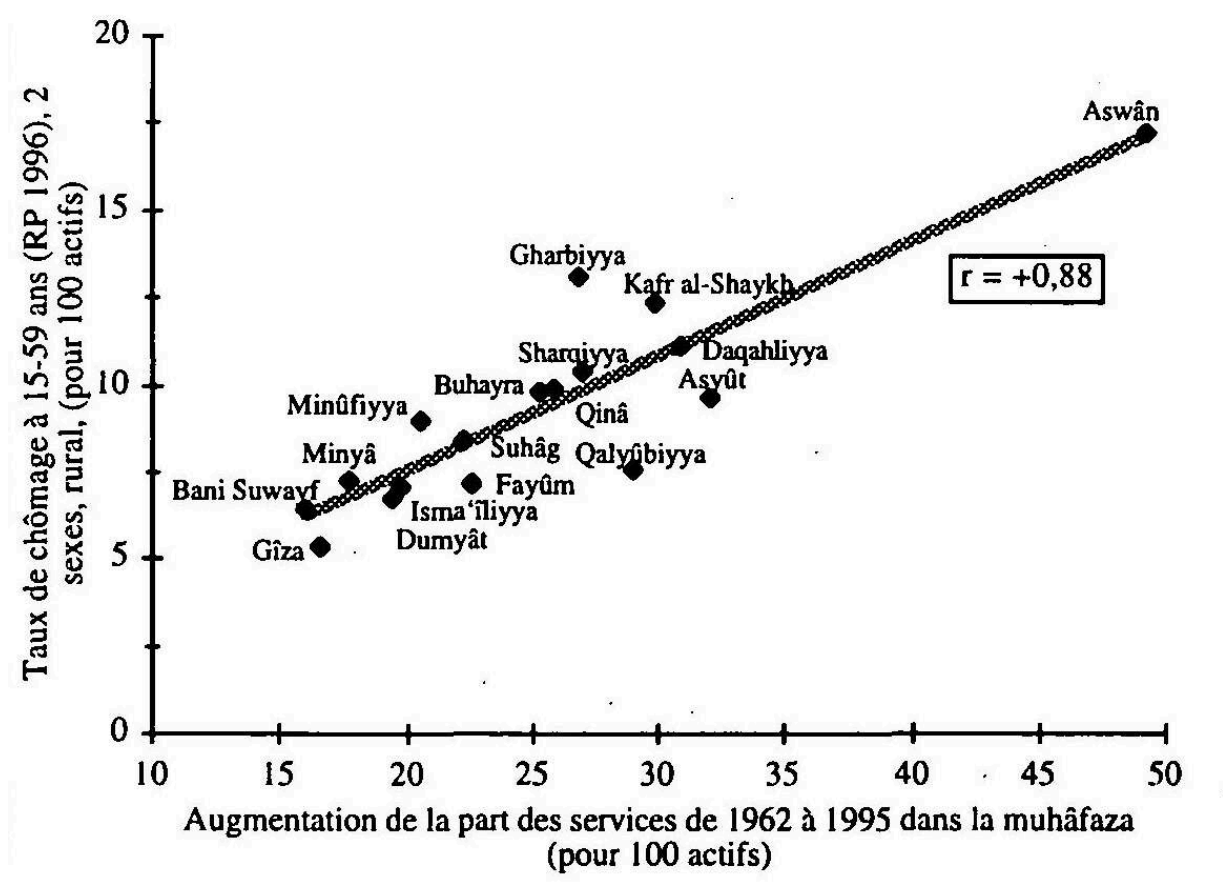

\section{NOTES}

1. En Europe, c'est la délocalisation du travail vers des pays de bas salaires que pointe le sens commun. Dans un pays de bas salaires comme l'Égypte, on invoque à l'inverse la suppression du travail local par l'importation de biens produits par des économies à technologies plus capitalistiques (Sabrî Abdallah, 1990). Dans tous les cas, l'étranger est tenu pour responsable.

2. Divers auteurs développent ces facteurs, par exemple Ezz al-Arab (1990).

3. L'exploitation par sondage des registres de ce recensement fait l'objet d'un programme du Cedej. Voir Alleaume G. et Fargues Ph., à paraitre, «La naissance d'une statistique d'État: le recensement de 1848 en Égypte ", dans Histoire et mesure.

4. L'enquête sur l'emploi de 1995 donne $11,3 \%$ de chômeurs. Les données préliminaires du recensement de 1996 indiquent au contraire qu'un tassement serait survenu : 9,7 \% de chômeurs dans la population active totale, contre 10,8\% au recensement précédent (1986).

5. Curieusement, les économistes y prêtent peu d'attention. L'un des ouvrages les plus récents sur l'économie de l'Égypte (Harik, 1997) ne mentionne même pas le mot. Même absence d'intérêt vingt ans plus tôt, dans les deux gros volumes de l'ouvrage qui dressait un premier bilan de l'infitâh en appliquant à l'Égypte les thèses de l'école de l'économie de la dépendance (Husayn, 1982).

6. Voir les actes du colloque organisé en 1989 par l'Université du Caire (Suleiman, 1989), en particulier Al-Khawâga (1989); voir également Handoussa (1991).

7. La naissance de la catégorie statistique "chômeur» et l'affinage de sa mesure sont historiquement liés au traitement social et politique des «classes dangereuses » dans un pays comme la France (voir Topalov, 1994). En Égypte, Wahdân avance que les évolutions du chômage et de la criminalité sont parallèles (Wahdân, 1991).

8. On réserve souvent la catégorie du sous-emploi ainsi définie aux économies «en développement ", par opposition au chômage, plutôt caractéristique des économies industrielles. 
Cette vision dualiste résiste mal à l'analyse comparative ou historique. Pour une discussion dans le cas de l'Égypte, voir Fergany (1990 et 1997b).

9. On trouvera une discussion philosophique dans Méda (1995).

10. Ces proportions sont sans doute surestimées car l'activité passée est sous-estimée chez les chômeurs. L'enquête de 1988 , avec un relevé très minutieux de toute période d'activité aussi réduite qu'elle ait pu être, ramenait à $57 \%$ la proportion des nouveaux entrants sur le marché du travail parmi les chômeurs (Fergany, 1990). Le protocole de cette enquête demeura expérimental et ne fut jamais repris dans les éditions suivantes.

11. Pour y répondre, il faudrait une enquête longitudinale ou rétrospective dans laquelle les personnes seraient interrogées non seulement sur leur situation présente mais sur leur histoire.

12. Les privatisations de grandes entreprises publiques, dans l'industrie et les services, pourraient renverser cette tendance.

13. L'enquête expérimentale de 1988 (Fergany, 1990), qui mesura avec précision la durée de travail, reste la seule source en la matière.

14. De nombreux auteurs ont traité ce sujet. Voir par exemple Karshenas (1997) et Shami (1990).

15. Ce n'est que depuis 1990 que les publications de cette enquête annuelle permettent de calculer le chômage par âge. Les enquêtes précédentes, dont le plan de publication varie d'une année à l'autre, ne fournissent pas les données nécessaires à la reconstitution de générations.

16. Les "générations 1970-1974 " forment le groupe d'âge 15-19 ans en 1990 et 20-24 ans en 1995, les « générations 1965-1969 » les groupes d' âge 20-24 et 25-29 ans aux mêmes dates.

17. Le recensement de 1986 est à ce jour la dernière source permettant de croiser l'activité, l'âge et l'état matrimonial. Il donne les taux d'activité féminine suivants (pour 100). À 20-24 ans : 8,5 pour les femmes mariées, divorcées ou veuves et 25,6 pour les célibataires ; à 25-29 ans : 13,0 et 38,0 ; à 30-34 ans : 13,8 et 34,5; à 35-39 ans : 9,5 et 29,0 .

18. Les diplômés forment à cette date $35,3 \%$ des actifs ayant un emploi.

19. On trouvera cette discussion dans Fergany (1996) pour qui le fait principal est un rendement privé de plus en plus faible de l'éducation, en accès au travail comme en rémunération.

20. Le logement fait exception pour les chefs de ménage chômeurs n'ayant jamais travaillé, qui dépensent sur ce poste plus que la moyenne des ménages. Cette dépense est à lier à une dimension du ménage plus petite ( 3 personnes, contre 4,7 en moyenne), qui élève le coût moyen du logement par personne.

21. Cette section analyse une matrice de corrélation qu'il aurait été fastidieux de reproduire ici : 45 indicateurs du chômage et de la création ou suppression d'emploi (selon la date, l'âge, le sexe et le milieu de résidence) sont corrélés avec 35 indicateurs de la démographie, du développement, de la répartition sectorielle de la population active, de l'instruction par groupe de générations, du tissu associatif et des structures familiales, dans le découpage des muhâfadhât. Cette matrice montre des covariations spatiales, qu'il faut se garder d'interpréter comme des causalités.

22. Voir par exemple Mohie El-Din(1977) ; Shenouda(1991) ; Ezz al-Arab(1989) ; Sabrî Abdallah (1990).

23. L'analyse de ce ralentissement, attribuable à la baisse de la fécondité, est donnée dans Fargues (1997).

24. Les indicateurs suivants ont été testés : croissance de la population totale, de la population d'âges actifs, des effectifs entrant à ces âges (20-24 ans) pour la démographie ; niveau et évolution des taux de chômage par sexe et âge sur le long (1962-1995) et le court terme (1990-1995), création nette d'emplois entre 1990 et 1995 . Tous les coefficients de corrélation linéaire entre ces indicateurs pris deux à deux (définis par muhâfadha avec distinction des secteurs urbain et rural) sont non significativement différents de 0 .

25. La proportion de la population qui se situe au-dessous de la « ligne de pauvreté » (estimée à 1 084 livres égyptiennes par personne et par an aux prix de 1996) est passée de 30,2\% en 
1981-1982, à 39,1\% en 1991-1992 et 47,6 \% en en 1995-1996. Interrogés sur l'évolution de leur situation entre 1991 et 1996, 42 \% des pauvres estiment qu'elle a empiré et $23 \%$ qu'elle s'est améliorée ; le rapport est inverse chez les non-pauvres (33 \% et 50 \%) (Nassef, 1996).

26. Nassef (1996) ; Assaad, Rouchdy (1998) ; Joliffe (1997).

27. C'est l'opinion de Fergany (1997).

28. Le coefficient de corrélation linéaire entre la proportion de pauvres en 1995-1996 et le nombre moyen d'années de scolarisation dans la population âgée de 10 ans et plus au recensement de 1996 est de - 0,60 en milieu urbain et - 0,78 en milieu rural. L'élévation du niveau d'éducation, mesurée par la différence entre les nombres moyens d'années scolaires des générations 1929-33 et 1964-68 - les plus récentes à avoir achevé leur scolarisation -donne les corrélations suivantes avec le taux de chômage (1995) : + 0,70 en milieu urbain et $+0,61$ en milieu rural ; corrélation tout aussi élevée avec la progression du chômage entre 1962 et $1995:+0,65$ pour le sexe masculin en milieu urbain.

29. La corrélation entre le nombre moyen d'années scolaires des générations 1930-1934 et le taux de chômage en 1962 est même particulièrement forte : + 0,79 (hommes urbains).

30. La corrélation la plus élevée est entre l'indice de développement humain et le taux de chômage à 20-24 ans en milieu rural (1990) : + 0,78 pour les femmes et $+0,70$ pour les hommes.

31. Hors gouvernorats urbains.

32. La corrélation est particulièrement forte entre la part de l'agriculture et le taux de chômage féminin en 1990 : - 0,83 en milieu rural et - 0,70 tous milieux confondus.

33. Définies comme la différence entre les effectifs d'actifs occupés en 1995 et en 1990, dans les générations 1966-1970.

34. Les agriculteurs ne forment que $6 \%$ des chômeurs ayant déjà travaillé (1995), eux-mêmes une toute petite minorité des chômeurs (4\%).

35. Par exemple, le taux de chômage masculin urbain en 1995 (tous âges) donne une corrélation de - 0,80 avec la part de l'industrie en 1995 et de - 0,74 avec l'évolution de cette part.

36. Le Fonds social de développement, institué en 1991 afin d'alléger les effets pervers de la réforme économique, encourage notamment les créations de petites et moyennes entreprises pour développer l'emploi.

37. Les corrélations sont exceptionnellement élevées. Par exemple, l'évolution de la part des services entre 1962 et 1995 donne une corrélation de + 0,88 avec le taux de chômage rural (2 sexes) en 1986, de $+0,72$ et $+0,81$ avec le taux de chômage masculin rural à 20-24 et 25-29 ans respectivement (1995), de + 0,79 avec l'évolution du chômage masculin rural entre 1962 et 1995, de $+0,72$ avec le chômage féminin urbain, etc.

38. Entre la part des activités de services et le PNB/hab., on trouve une corrélation linéaire de + 0,80 .

39. L'enquête sur l'emploi de 1995 permet de calculer les nombres moyens d'années scolaires suivants parmi la population active occupée. Agriculture : 1,5 an; industrie : 4,8; services : 7,5.

40. Aswan, qui venait en $9^{e}$ position par la place de l'industrie (construction incluse) en 1962, est tombée à l'avant-dernier rang en 1995. Cette muhâfadha est la seule à avoir perdu de l'emploi industriel (en pourcentage des actifs) entre 1962 et 1995, avec Port-Sa'îd et Suez, sinistrées par la guerre avec Israël.

41. L'enquête de 1962 révèle une corrélation positive presque parfaite entre le chômage masculin urbain et la part des activités de services $(+0,91)$ et une corrélation opposée avec la part de l'agriculture $(-0,89)$.

42. Elle n'a changé que modérément: la répartition des activités par secteur et les niveaux d'éducation relatifs à l'année 1962 donnent des corrélations très élevées avec les indicateurs du chômage 30 ans plus tard (1995), signe d'une inertie des facteurs. 
INDEX

Mots-clés : chômage, statistiques

\section{AUTEUR}

PHILIPPE FARGUES

Cedej 